\title{
WHAT IS THE ORIGIN OF THE LABYRINTHINE ARTERY AMONG BLACK KENYANS?
}

\author{
Julius A. Ogeng'o, Beda O. Olabu, Phillip M. Mwachaka, Beryl S. Ominde, Martin I. Inyimili \\ Department of Human Anatomy, University of Nairobi, P.O. Box 30197 - 00100; Email uonbi.ac.ke.
}

\section{ABSTRACT}

Origin of labyrinthine artery is important because it influences the presentation of occlusion of anterior inferior cerebellar and basilar arteries. It shows ethnic and geographical variation, but there is no data from black African populations. This study, therefore examined the pattern of origin of labyrinthine artery in adult black Kenyans. Three hundred and fourty six arteries from one hundred and seventy-three formalin fixed brains were examined by dissection at the Department of Human Anatomy University of Nairobi, Kenya. Labyrinthine artery arose from basilar artery in 260 (75.1\%); as common trunk with anterior inferior cerebellar artery in 48 (13.9\%) and from the latter in $38(11.0 \%)$ of cases. There was no side and gender difference in the pattern of origin. This implies that majority of labyrinthine arteries arise from basilar artery, different from that in oriental, Indo-Asian and Caucasian populations, in which it arises from the anterior inferior cerebellar artery. Preoperative evaluation of basilar artery branching is recommended.

Keywords: labyrinthine artery, origin, Kenyan, Basilar, AICA

\section{INTRODUCTION}

The labyrinthine artery (LA), also called internal auditory artery, is an end artery which supplies the inner ear, facial and vestibulocochlear nerves. This artery was classically known to arise from the basilar artery (BA) until Nabeya (1923) and Adachi (1928) reported that it consistently arose from the anterior inferior cerebellar artery (AICA) especially among Japanese (Nager, 1954). Some textbooks still describe it as a branch of BA (Tobias et al., 2001). Generally, howeve, $r$ the variable origin from either BA or AICA is now well entrenched (Gabella, 1999; Sinnatamby, 2001; Sunderland, 1945, 1948; Sakata 2001; Wankhede et al., 2015; Haidera, 2015). Features of its occlusion, namely vertigo, deafness, facial palsy, constituting the so called labyrinthine artery infarction are associated with infarction of brainstem and/or cerebellum especially in the territory of AICA (Lee et al., 2009; Kim and Lee, 2009; Haidara et al., 2015). What is not so well known is that other than BA and AICA, the LA could arise from several other sources (Wende, 1975; Harrigan et al., 2009). Knowledge of variation in origin of this artery is important in order to avoid inadvertent ligation or sectioning of the arteries during surgical approaches to the posterior cranial fossa and especially cerebello - pontine angle for aneurysms, arteriovenous malformations, tumors, epilepsy surgery, posterior temporal lobectomies and posterior cerebral revascularization (Uchino et al., 2003; Pai et al., 2007; Zador et al., 2010; Haidara et al., 2015). Further, they are also important during diagnostic and interventional neuroradiology in avoiding incorrect diagnosis, explaining unusual presentation of posterior circulatory stroke, possible implications of surgery and interventional procedures (Bulsara et al., 2007; Bykowski et al., 2011). The patterns of origin display ethnic variations (Gillilan et al., 1972). As advances in neurosurgery including for tumors increases in Africa (Qureshi and oluoch - Olunya, 2010; Uduma et al., 2013), there is need for accurate knowledge on brain vasculature. Such data on LA from black populations are, however, scanty and absent altogether for the Kenyan one. This study therefore investigated the origin of LA in a black Kenyan population.

Submitted $7^{\text {th }}$ June 2017, revised on $29^{\text {th }}$ June 2017. Published online $12^{\text {th }}$ July 2017. To cite: Ogeng'o J, Olabu B, Mwachaka, Ominde B, Inyimili M. What is the origin of the labyrinthine artery among black Kenyans? Anatomy Journal of Africa. 2017 . Vol 6 (2): $982-986$. 


\section{MATERIALS AND METHODS}

One hundred and seventy-three (99 male, 74 female) brains, that is, 346 arteries were examined. In these, the arachnoid was gently peeled off the base of brain. Labyrinthine artery was identified as that which coursed laterally towards cerebellopontine angle to join the facial and vestibulo cochlea nerves. Arteries were defined as common trunks if their branches were of almost equal diameter on macroscopic examination. Where one branch was smaller, the larger one was considered the parent. Each artery was followed distally to ascertain its destination. Its site and pattern of origin were then recorded. Photographs of representative patterns were taken using a high resolution digital camera. Respective origins of the arteries were coded and entered the statistical program for Social Scientists version 16.0 for windows. The data were analysed for frequencies. Student t-test was used to calculate statistical difference between left and right and between male and female at $95 \%$ confidence interval where $p$ value of $\leq 0.05$ was taken to be significant.

\section{RESULTS}

The single LA was present in all cases. It arose from the basilar (Fig 1A) in $260(75.1 \%)$ cases. 132 of these were in females, and 128 in males. This difference was not statistically significant $(p=0.09)$. 125 were on the left and 135 on the right ( $p=0.07)$.
In $48(13.9 \%)$ cases, it arose as a common trunk with AICA (Fig 1B) and from AICA (Fig 1C) in 38 $(11.0 \%)$ cases. There was no gender nor side difference in these either.

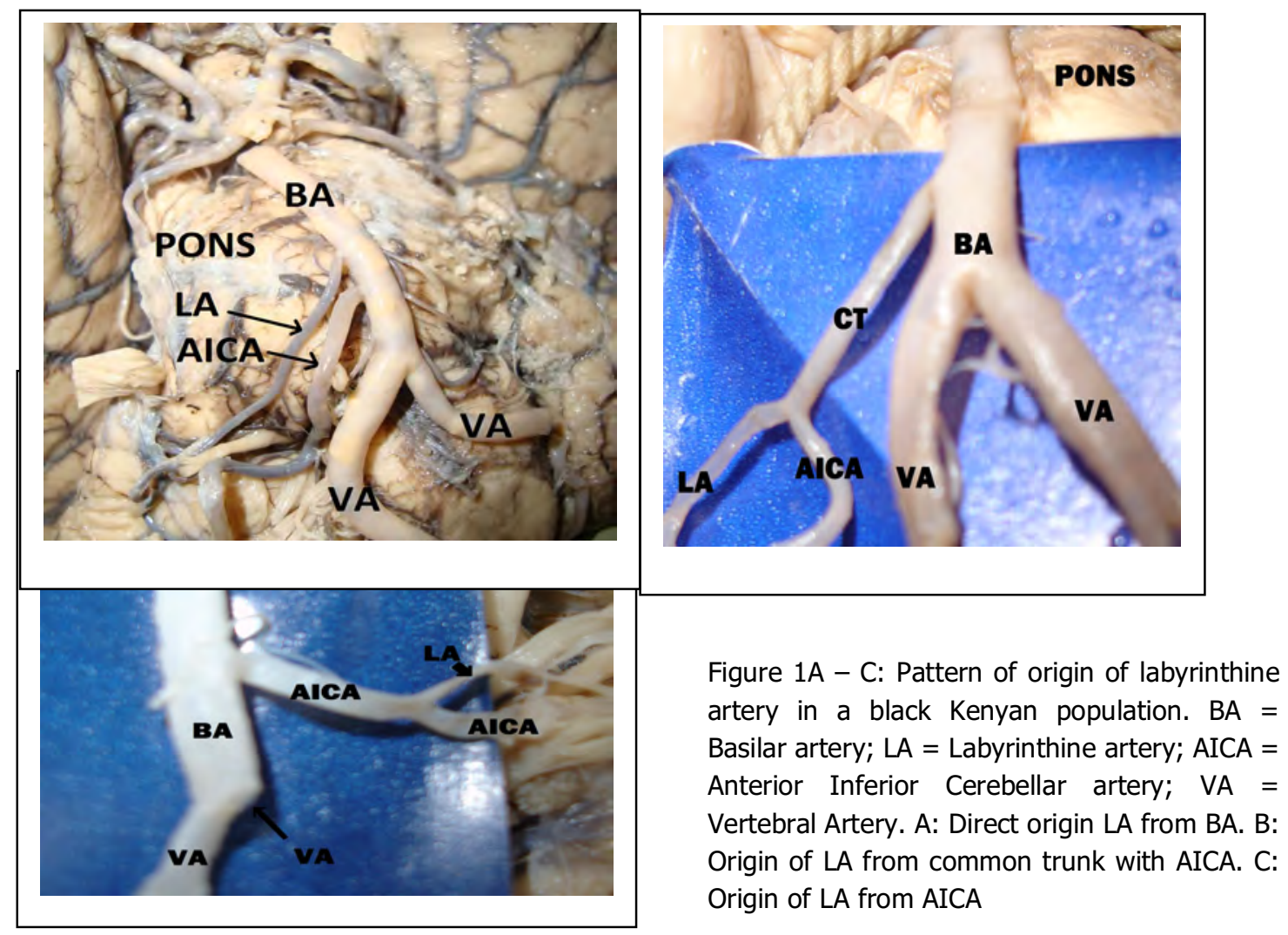




\section{DISCUSSION}

The contemporary view is that LA usually arises from AICA, but may also arise from BA (Gabella, 1999; Sinnatamby, 2001; Zhang et al., 2002; Haidara et sl., 2015). Observations of the current study, however, reveal that this artery arose from basilar in (75.1\%) of cases, much higher than in prevailing reports where the frequency varied from $7.7 \%$ among Koreans (Kim et al., 1990) to $67.7 \%$ among Italians (Cavatori, 1908). Although most reports show the predominant origin to be AICA, the frequency varies [Table 1].

Such wide variability is consistent with literature ascertions that this artery may vary even between the two sides of the same individual (Wende, 1975; Boborelu et al., 2012; Wankhede et al., 2015)

In the current study, the origin predominantly from the basilar artery is consistent with reports that acute auditory symptoms from vertebrobasilar insufficiency are usually associated with multiple brain stem and cerebellar signs (Huang et al., 1993; Lee et al., 2011). This implies that in this study population, posterior circulatory stroke due to vertebrobasilar insufficiency is much more likely to present with vestibulocochlear deficits and should therefore be considered a differential diagnosis in the latter.

Labyrinthine artery arose from AICA or as a common trunk with it in only $25 \%$ cases. Origin from a common trunk with AICA though seldom reported, exists in historical accounts (Henle, 1876). Although this association with AICA is much lower than that reported in previous studies (Table 1), it is still clinically significant. Accordingly, vestibulochoclear loss, common in acute ischemic stroke in the distribution of AICA in other populations (Melling and Koos, 1996; Lee, 2014; Kim and Lee, 2017) may occur in only one in four of the Kenyan populations.

Table 1: Pattern of origin of labyrinthine artery in various populations

\begin{tabular}{|c|c|c|c|c|c|c|c|}
\hline \multirow[t]{2}{*}{ Author } & \multirow[t]{2}{*}{ Population } & \multicolumn{6}{|c|}{ Origin of labyrinthine artery (\%) } \\
\hline & & BA & AICA & SCA & PICA & VA & AICA - LA trunk \\
\hline Adachi, 1928 & Japanesse & - & 100 & - & - & - & - \\
\hline Cavatori, 1908 & Italian & 67.7 & 32.3 & - & - & - & - \\
\hline Haidara et al., 2015 & West African & 10 & 90 & - & - & - & - \\
\hline Harrigan et al., 2009 & Unspecified & 16 & 45 & 25 & - & - & - \\
\hline Kim et al., 1990 & Korean & 7.7 & 92.3 & - & - & - & - \\
\hline Padmavathi, 2005 & Indian & 30.6 & 63.9 & - & - & - & - \\
\hline Sunderland, 1948 & Unspecified & 17 & 83 & - & - & - & - \\
\hline Wanhkede, 2015 & Indian & 35 & 65 & - & - & - & - \\
\hline Wende et al., 1975 & German & 16 & 45.4 & 24.4 & 5.4 & & - \\
\hline Zhang et al., 2002 & Chinese & 12.3 & 83.6 & - & - & - & - \\
\hline Current study & Kenyan & 75.1 & 11.0 & - & - & - & 13.9 \\
\hline
\end{tabular}

Key: $\mathrm{BA}=$ Basilar Artery; AICA = Anterior Inferior Cerebellar Artery; PICA = Posterior Inferior Cerebellar Artery; $\mathrm{VA}=$ Vertebral Artery 
Partial ischaemia in the AICA territory could lead to isolated acute auditory syndrome such as hearing loss and tinnitus. Indeed hearing loss and vestibular disorders including vestibular neuritis or Meniere's disease are common signs of AICA infarct (Lee et al., 2002). Accordingly, a detailed neurological examination focusing on additional brainstem and cerebellar signs should be performed on all patients presenting with vertigo (Lee and Cho, 2003).

In conclusion, a majority of the labyrinthine arteries arise from the basilar artery, different from contemporary reports from Oriental, Indo-Asian and Caucasian populations in which it arises from the anterior inferior cerebellar artery. Patients with audiovestibular symptoms should be examined for brainstem and cerebellar dysfunction.

ACKNOWLEDGEMENT: We are grateful to Acleus Murunga and Jacob Gimongo for technical support and Antonina Odock - Opiko for typing this manuscript

CONFLICT OF INTEREST: There is no conflict of interest

\section{REFERENCES}

1. Adachi B. 1928. Das Artieriensytem dev Japanese, Bd 1, Kioto.

2. Boborelu GN, Totolin M, Mindrila I, Mesina M. 2012. Anatomic investigation of the internal acoustic meatus vascularization. Rom J Funct Clin Macro Microscop Anat Anthropol, 11: $426-430$.

3. Bulsara KR, Zomorodi A, Provensale JM. 2007. Anatomic variant of the posterior cerebral artery.Am J Roentgen; 185: w 395.

4. Bykowski J, Jahan R, Pakbaz RS. 2011. Variant carotid origin of left anterior inferior cerebellar artery mimicking infarct on angiography. J Neuro Intervent Surge; doi: 10.1136/jnls.2010.00 3822.

5. Cavatori P. 1908. II tipo normale ele variazoni delle arterie della base del encefalo nell vomo. Monitore 2001 Ital: 19: $248-258$.

6. Gabella G. 1999. Cardiovascular system: Labyrinthim artery: IN Grays Anatomy, Ed Williams et al 38 Edition pp 1534.

7. Gillilan LA. 1972. Anatomy and Embryology of the arterial system of the brain stem and cerebellum. In: Handbook of clinical Neurology eds Vinken IJ, Bryn G. vol 2 North Holland; Amsterdam pp 24 44.

8. Haidara A, Peltier J, Zunon - Kupre Y, N'da HA, Droogba L, Gars DL. 2015. Microsurgical anatomy of the Labyrinthine artery and clinical relevance. Turk Neurosurg; 25: 539 - 543.

9. Harrigan MR, Deveikis JP, Ardelt AA. 2009. Handbook of cerebrovascular disease and neurointerventional technique. Humana Press, Springer Science + Business Media. Essential neurovascular Anatomy. Basilar artery: pp $59-61$.

10. Henle J. 1876. Handbuch der systematischen Anatomie des Menschen Bd 3 (Gefassiehre), I. Abt, F. Viewieg.

11. Huang $\mathrm{MH}$, Huang CC, Ryu SJ et al. 1993. Sudden bilateral hearing impairment in vertebrobasilar occlusive disease. Stroke; 24: 132 - 7.

12. Kim HA, Lee H. 2017. Recent advances in understanding audiovestibular loss of a vascular cause. J . Stroke; 19: $61-66$.

13. Kim HA, Yi HA, Lee H. 2016. Recent advance in cerebellar ischemic stroke syndromes causing vertigo and hearing loss. Cerebellum, 15; $781-788$.

14. Kim HN, Kim YH, Park IY, Kim GR, Chung IH. 1990.Variability of the surgical anatomy of the neurovascular complex of the cerebellopontine angle. Ann Otol Rhinol Laryngol; 99: 288 - 296.

15. Kim JS, Lee H. 2009. Inner ear dysfunction due to vertebrobasilar ischaemic stroke. Semin Neurol; 29: $534-540$. 
16. Lee $\mathrm{H}$, Cho Y-W. 2003. Auditory disturbance as a prodrome of anterior inferior cerebellar artery Infarction. J Neurol Neurosurg Psychiatry; 74: 1644 - 1648.

17. Lee H, Kim S, Chung EJ et al. 2009. Infarction in the territory of anterior inferior cerebellar artery. Spectrum of audiovisual loss. Stroke, 40:3745 -3751.

18. Lee H, SohnS-II, Juang D-K, Cho Y-W, Lim J-G, Yi S-D et al. 2002. Sudden deafness and Anterior Inferior Cerebellar Artery Infarction Stroke; 33: 2807 - 2812.

19. Lee H. 2009. Neuro - otological aspects of cerebellar stroke syndrome. J Clin Neurol; 5: 65 - 73.

20. Lee H. 2014. Isolated Vertigo. J Stroke, 16P: $124-130$.

21. Melling M, Koos WT. 1996. Abnormality of the labyrinthine artery and its topographical relation to the abducent nerve. Acta Anatomica, 1956: 151 - 154.

22. Nabeya D. 1923. A study in the comparative anatomy of the blood vascular system of the internal ear in mammalia and homo (Japanese) - Acta Scholae Medicinalis Univ Imp Kioto, 4: 1 - 132.

23. Nager GT. 1954. Origins and Relations of the internal auditory artery and the subarcuate artery. Ann Otol Rhinol Laryngol; 63.

24. Padmavathi G. 2005. Study of basilar artery in Human cadavers. MD thesis, Rajiv Gandhi University pp 50, 61, $67-69$.

25. Pai BS, Varma RG, Kulkarni RN, Nirmala S, Manjnath LC, Rakshith S. 2007. Microsurgical anatomy of the posterior circulation. Neurol India; 55: $31-41$.

26. Qureshi MM, Oluoch - Olunya D. 2010. History of neurosurgery in Kenya, East Africa. World Neurosurg; 73: $261-263$.

27. Sakata S. 2001. Microsurgical anatomy of the basilar artery. Surgical approaches to the basilar trunk and vertebrobasilar junction aneurysm. Korean J Cerebrovasc Dis, 3: 5 - 10.

28. Sinnatamby CS. 2001. Last's Anatomy: Regional and applied. $12^{\text {th }}$ Edition Churchill Livingstone. Pp 445.

29. Sunderland S. 1945. The arterial relations of the internal auditory meatus. Brain; 68: $23-27$.

30. Sunderland S. 1948. Anatomy of the base of the brain. Montefiore Medical Library Neurovascular relations and anomalies at the base of the brain; pp $243-257$.

31. Tobias PV, Arnold M, Allan JC. 2001. Man's Anatomy; A study in dissection, Head, Neck and Central Nervous System. Witwatersand University Press pp 243.

32. Uchino A, Sawada A, Takase Y, Kudo S. 2003. Variations of the superior cerebellar artery. MR angiographic demonstration. Radiat Med; 21: 235 - 238.

33. Uduma UF, Emejulu JK, Motah M. 2013. Intracranial meningiomas in the present era of modern neuroimaging: diagnostic and management options, with radiological illustrations. Orient J Med, 25: $67-74$.

34. Wankhede HA, Nimje DA, Hosmani PB. 2015. Variations in the branches of basilar artery in adult human cadavers. Asian Pac J Health Sci, 2: 161 - 166.

35. Wende S, Nakayama N, Schwerdtfeger P. 1975. The internal auditory artery (embryology, anatomy angiography, pathology. J Neurol 175; 210: $21-31$.

36. Zador Z, Lu DC, Lawton MT. 2010. Deep bypasses to the distal posterior circulation: anatomical and clinical comparison of pretemporal and subtemporal approaches. Neurosurgery; 66: $192-200$.

37. Zhang K, Wang F, Zhang Y, Li M, Shi X. 2002. Anatomic investigation of the labyrinthine artery. Zhonghua Er Bi Yan Hou Ke Za Zhi; 37: 103 - 105. 